\title{
EFFISIENSI PRODUKSI INDUSTRI SKALA KECIL BATIK SEMARANG: PENDEKATAN FUNGSI PRODUKSI FRONTIER STOKASTIK
}

\author{
Ngatindriatun (atinudinus@yahoo.com) \\ Hertiana Ikasari (ihertiana@yahoo.co.id) \\ Universitas Dian Nuswantoro Semarang
}

\begin{abstract}
Batik is known since 17th century. In 2009, UNESCO took batik as the world heritage. Likewise, Batik Semarang. Batik Semarang is unpopular than other batik's products on Central Java. Their productivity is on small scale and only for environment surroundings. The small productivity causes the high price on their product selling. The aims of this research is to estimate the function of production and technical efficiency of batik Semarang. Sample are 67 owners of small scale batik Semarang industry. Analysis instrument is Stochastic Frontier Production Function. The measuring of production efficiency are material, support material, labor force, instruments, kerosene, firewood, and large of trade location. The result shows that free variable is found significant and have an appropriate signal. Other result shows that technical efficiency of batik Semarang industry is $88,9 \%$
\end{abstract}

Key Words : Batik Semarang, Technical Efficiency, Stochastic Frontier Production Function.

\section{PENDAHULUAN}

Batik merupakan salah satu produk unggulan yang dimiliki setiap kabupaten dan kota di Jawa Tengah, yang banyak dikelola UKM (Jawatengah go.id, 2004). Batik telah dikenal sejak abad XVII, dan pada tahun 2009 telah mendapat pengakuan dari badan PBB yaitu UNESCO sebagai world heritage. Pengakuan batik tulis ini akan menambah nilai tambah bagi pengembangan batik (Waspada Online, 2008). Demikian halnya dengan batik semarang.

Dahulu kota Semarang pernah jaya di bidang usaha batik, sama seperti Kota Solo dan Pekalongan. Hal ini bisa dibuktikan dengan sebutan kampung batik di Kota Semarang. Namun sangat disayangkan usaha batik di Kota Semarang saat ini hampir punah. Selain hilangnya seni budaya yang dimiliki juga lepasnya kesempatan meraih keuntungan dari maraknya bisnis batik yang saat ini mulai laku keras (Pemkot Semarang, 2009). Saat ini kota Semarang baru memiliki 67 usaha batik. Usaha batik tersebut tersebar di beberapa kecamatan yang ada di Kota Semarang (Disperindag Kota Semarang, 2009). Namun kondisi usaha batik Semarang saat ini belum tersentuh untuk ikut menyemarakkan bisnis batik dengan peningkatan produksi dan pemasaran.

Perusahaan kecil dimana manajemen dikelola sendiri oleh pemiliknya, laba mendominasi keputusan hampir seluruh perusahaan. Tidak seperti halnya pada industry besar, manajer mungkin lebih memperhatikan pada tujuan seperti maksimisasi penerimaan untuk mencapai pertumbuhan atau memuaskan stakeholders daripada maksimisasi laba (Pyndick dan Rubinfeld, 2005). Demikian halnya seperti pada kegiatan berproduksi bagi usaha kecil, tujuan usaha kecil batik adalah memaksimalkan keuntungan usaha. Perolehan keuntungan maksimum berkaitan erat dengan efisiensi dalam berproduksi. Proses produksi tidak efisien dapat disebabkan karena secara teknis tidak efisien. Hal ini terjadi karena produktivitas maksimum tidak tercapai. Penyebab lain secara alokatif tidak efisien karena pada tingkat harga tertentu, proporsi penggunaan input tidak optimum. Hal ini terjadi karena produk penerimaan marjinal (marginal revenue product) tidak sama dengan biaya marjinal (marginal cost) dari input yang digunakan. Pada umumnya orientasi para perajin batik merupakan suatu komunitas yang relatif homogen yang cenderung menginginkan efisiensi teknis atau sebagai upaya memaksimalkan produktivitas. Dalam kenyataanya, perajin dan usaha batik tidak selalu dapat mencapai tingkat efisiensi teknis seperti yang diharapkan. 
Berdasarkan prasurvey terhadap perajin batik di Semarang, pada umumnya mengalami kesulitan dalam memaksimalkan produktivitas. Kesulitan tersebut dikarenakan kurangnya tenaga kerja yang memiliki seni membatik, kurangnya permodalan untuk mengembangkan bahkan untuk membuka usaha batik. Masyarakat di Semarang enggan membuka usaha batik dikarenakan ada anggapan bahwa untuk membuka usaha baru di bidang batik memerlukan modal yang cukup besar.. Sementara usaha batik yang saat ini telah ada, skala usahanya masih merupakan usaha kecil dan jumlah yang diproduksi masih rendah. Jumlah produksi yang rendah mengakibatkan biaya produksi rata-rata menjadi tinggi.

Pencapaian efisiensi teknik yang tinggi sangat penting dalam upaya meningkatkan tingkat kompetitif dan keuntungan suatu usaha. Efisiensi teknik merupakan salah satu komponen dari keseluruhan efisiensi ekonomi. Akan tetapi suatu usaha batik baru dikatakan efisien secara ekonomi jika efisiensi teknik telah tercapai. Berdasarkan hal tersebut, maka dalam tujuan penelitian ini untuk menganalisis efisiensi teknik usaha kecil batik Semarang.

\section{LANDASAN TEORI DAN PENGEMBANGAN HIPOTESIS}

\section{Usaha Kecil dan Menengah}

Beberapa lembaga atau instansi bahkan UU memberikan definisi Usaha Kecil Menengah (UKM). Badan Pusat Statistik (BPS) memberikan definisi UKM berdasarkan kuantitas tenaga kerja. Usaha kecil merupakan entitas usaha yang memiliki jumlah tenaga kerja 5 s.d 19 orang, sedangkan usaha menengah merupakan entitias usaha yang memiliki tenaga kerja 20 s.d. 99 orang. Kementrian Menteri Negara Koperasi dan Usaha Kecil Menengah (Menegkop dan UKM), memberikan definisi yang berbeda. Demikian juga menurut UndangUndang No. 20 Tahun 2008. Definisi tersebut dapat dilihat pada Tabel 2.1.

Tabel 2.1. Kriteria UMKM Berdasarkan Jumlah Aset dan Omset

\begin{tabular}{|c|c|c|c|c|c|}
\hline \multirow[t]{2}{*}{ No } & \multirow{2}{*}{ Usaha } & \multicolumn{2}{|c|}{ Menurut Menegkop dan UKM } & \multicolumn{2}{|c|}{ Menurut UU No 20 Tahun 2008} \\
\hline & & Asset & Omzet & Asset & Omzet \\
\hline 1 & Usaha Kecil & $<200$ juta & < 1 Miliar & 50 Juta - 500 Juta & $\begin{array}{l}300 \text { Juta - 2,5 } \\
\text { Miliar }\end{array}$ \\
\hline 2 & UsahaMenengah & $\begin{array}{l}200 \text { juta }-10 \\
\text { miliar }\end{array}$ & & 500 Juta - 10 Miliar & $\begin{array}{l}2,5 \text { Miliar - } 50 \\
\text { Miliar }\end{array}$ \\
\hline
\end{tabular}

Sumber: Menegkop dan UKM ; UU no. 20 Tahun 2008

Dalam perspektif perkembangannya, UKM dapat diklasifikasikan menjadi 4 (empat) kelompok yaitu :

- Livelihood Activities,

merupakan Usaha Kecil Menengah yang digunakan sebagai kesempatan kerja untuk mencari nafkah, yang lebih umum dikenal sebagai sektor informal. Contohnya adalah pedagang kaki lima.

- Micro Enterprise,

merupakan Usaha Kecil Menengah yang memiliki sifat pengrajin tetapi belum memiliki sifat kewirausahaan.

- Small Dynamic Enterprise,

merupakan Usaha Kecil Menengah yang telah memiliki jiwa kewirausahaan dan mampu menerima pekerjaan subkontrak dan ekspor

- Fast Moving Enterprise,

merupakam Usaha Kecil Menengah yang telah memiliki jiwa kewirausahaan dan akan melakukan transformasi menjadi Usaha Besar (UB).

Karakteristik UKM di Indonesia, berdasarkan penelitian yang dilakukan oleh AKATIGA, the Center for Micro and Small Enterprise Dynamic (CEMSED), dan The Center for Economic and Social Studies (CESS) pada tahun 2000, adalah mempunyai daya tahan untuk hidup dan 
mempunyai kemampuan untuk meningkatkan kinerjanya selama krisis ekonomi. Hal ini disebabkan oleh fleksibilitas UKM dalam melakukan penyesuaian proses produksinya, mampu berkembang dengan modal sendiri, mampu mengembalikan pinjaman dengan bunga tinggi dan tidak terlalu terlibat dalam hal birokrasi.

UKM di Indonesia dapat bertahan di masa krisis ekonomi disebabkan oleh 4 (empat) hal, yaitu : (1) Sebagian UKM menghasilkan barang-barang konsumsi (consumer goods), khususnya yang tidak tahan lama, (2) Mayoritas UKM lebih mengandalkan pada nonbanking financing dalam aspek pendanaan usaha, (3) Pada umumnya UKM melakukan spesialisasi produk yang ketat, dalam arti hanya memproduksi barang atau jasa tertentu saja, dan (4) Terbentuknya UKM baru sebagai akibat dari banyaknya pemutusan hubungan kerja di sektor formal.

UKM di Indonesia mempunyai peranan yang penting sebagai penopang perekonomian. Penggerak utama perekonomian di Indonesia selama ini pada dasarnya adalah sektor UKM. Berkaitan dengan hal ini, paling tidak terdapat beberapa fungsi utama UKM dalam menggerakan ekonomi Indonesia, yaitu (1) Sektor UKM sebagai penyedia lapangan kerja bagi jutaan orang yang tidak tertampung di sektor formal, (2) Sektor UKM mempunyai kontribusi terhadap pembentukan Produk Domestik Bruto (PDB), dan (3) Sektor UKM sebagai sumber penghasil devisa negara melalui ekspor berbagai jenis produk yang dihasilkan sektor ini.

Kekuatan dan kelemahan UKM menurut Afifah, 2009 dapat dilihat pada Tabel 2.2.

Tabel 2.2. Kekuatan dan Kelemahan UKM

\begin{tabular}{|l|l|}
\hline \multicolumn{1}{|c|}{ Kekuatan } & \multicolumn{1}{c|}{ Kelemahan } \\
\hline - Kebebasan untuk bertindak & - Relatif lemah dalam spesialisasi \\
- Menyesuaikan kepada kebutuhan & - Modal dalam pengembangan terbatas \\
setempat & - Sulit untuk mendapatkan karyawan yang \\
- Peran serta dalam melakukan & cakap \\
usaha/tindakan & \\
\hline
\end{tabular}

Sumber : Afifah, 2009

\section{Fungsi Produksi}

Fungsi produksi frontier menggambarkan produksi maksimum yang dapat dihasilkan untuk sejumlah masukan (input) produksi yang dikorbankan. Fungsi produksi Frontier pertama kali dikembangkan oleh Aigner et al.(1977) dan Meeusen dan Van den Broek (1977) melalui pendekatan Stochastic Production Frontier (SPF). Spesifikasi asli mencakup fungsi produksi dispesifikasi untuk data silang (cross-sectional data) yang mempunyai error term yang mempunyai dua komponen, satu disebabkan oleh random effects dan yang lain disebabkan oleh inefisiensi teknis. Soekartawi (2003) menjelaskan bahwa aplikasi fungsi produksi ini digunakan untuk mengukur bagaimana fungsi produksi sebenarnya terhadap posisi frontiernya. Pada awalnya fungsi atau model ini diaplikasikan untuk menganalisis ekonomi produksi pertanian yang kemudian aplikasinya berkembang pada bidang-bidang lain seperti keuangan, perikanan, manufaktur, dan lainnya. Battese dan Coelli (1992) mengajukan fungsi produksi frontier stokhastik untuk panel data (yang tidak seimbang) yang mempunyai pengaruh terhadap perusahaan yang diasumsikan didistribusikan sebagai truncated normal random variables, yang juga dibolehkan bervariasi dengan waktu.

Dalam banyak kenyataan, penggunaan fungsi produksi frontier dipakai untuk mengukur tingkatan efisiensi teknik dari suatu usaha. Pada penelitian Pagan (2003) menggunakan fungsi produksi frontier untuk mengukur efisiensi produksi perusahaan dan kompensasi eksekutif di Amerika Serikat. Model ini juga diaplikasikan untuk mengukur efisiensi teknik pada kapal ikan di Inggris (Pascoe dan Coglan, 2002). Soedantoko (2010) juga menggunakan 
fungsi produksi frontier untuk mengukur efisiensi teknik dan efisiensi alokatif pada usaha batik di Pekalongan, Jawa Tengah.

\section{Efisiensi}

Pengertian efisiensi adalah komponen produktivitas dan mengacu pada perbandingan aktual dan jumlah optimal dari input dan output (Lovell, 1993), di mana produktivitas merupakan hubungan antara output dan input dalam bentuk rasio. Susantun (2000) menyatakan bahwa pengertian efisiensi dalam produksi adalah perbandingan output dan input berhubungan dengan tercapainya output maksimum dengan sejumlah input, artinya apabila rasio output/input besar maka efisiensi dikatakan tinggi. Soekartawi (1990) mengartikan efisiensi sebagai upaya penggunaan input yang sekecil-kecilnya untuk mendapatkan produksi yang sebesar-besarnya, di mana situasi tersebut dapat terjadi apabila proses produksi membuat suatu upaya kalau nilai produk marginal untuk suatu input sama dengan harga input tersebut. Pada umumnya bertambahnya efisiensi disebabkan karena (Komaruddin, 19986) :

a. Penggunaan manajemen modern

b. Penggunaan sumber-sumber yang bukan manusia

c. Mekanisme yang dengan sendirinya dapat menyesuaikan diri

d. Pemakaian bagian-bagian alat-alat yang distandarisasikan dan dapat ditukarkan satu sama lain

e. Meninggalkan proses produksi yang kompleks dan menggantinya dengan pekerjaan dan produksi yang repetitif.

f. Pengkhususan tugas-tugas dan pembagian kerja dan wewenang.

Farell (1957) membedakan efisiensi menjadi tiga yaitu: efisiensi teknik, efisiensi alokatif (harga) dan efisiensi ekonomi.

\section{Efisiensi Teknis}

Farell dalam Waridin (2005) menyatakan bahwa technical efficiency merefleksikan kemampuan perusahaan untuk mendapat output maksimum dari satu set input yang tersedia. Efisiensi ini lebih mengacu kepada memaksimumkan output yang mungkin dengan sejumlah input (Worthington, 2004).

Bentuk umum fungsi produksi frontier stokastik adalah sebagai berikut :

$$
\left.Y_{i}=f(X) \beta\right) \varepsilon^{\varepsilon_{i}}
$$

Dimana,

$$
\begin{aligned}
& \mathrm{i} \quad=1,2, \ldots, \mathrm{n} \\
& \text { I } \quad=1,2, \ldots, \mathrm{L} \\
& \text { Yi = keluaran (output) yang dihasilkan oleh observasi ke-i } \\
& \mathrm{X}_{\mathrm{li}} \quad=\text { vektor masukan (input) } \mathrm{L} \text { yang digunakan oleh observasi ke-i } \\
& \beta=\text { vektor koefisien parameter } \\
& \text { हi = "galat khusus" dari observasi ke-i } \\
& =\mathrm{vi}-\mathrm{vi}
\end{aligned}
$$

Fungsi produksi frontier stokastik mempunyai galat khusus हi sehingga model menggunakan fungsi produksi tersebut disebut composed error model. Sifat kekhususannya adalah bahwa galat ini terdiri dari 2 unsur galat vi dan ui yang masing-masingnya mempunyai sebaran yang berbeda. Galat vi menangkap kesalahan variasi output yang disebabkan oleh faktorfaktor internal yaitu faktor-faktor yang dapat dikelola oleh produsen. Sebarannya 
diasumsikan asimetris dan distribusinya setengah normal. Dengan demikian ragam totalnya (varians) adalah :

$$
\sigma^{2}=\sigma^{2} v+\sigma^{2} U
$$

Menurut Battese dan Coelli (1995) variasi total output aktual terhadap frontier-nya adalah:

$$
\gamma=\frac{\sigma_{v}^{2}}{\sigma}
$$

Sedangkan Joundrow, et.al (1982) mengukur tingkat efisiensi teknis (technical efficiency - TE) sebagai berikut:

$$
\mathrm{TE}_{\mathrm{i}}=\exp \left[-\mathrm{E}\left(\mathrm{U}_{\mathrm{i}} / \varepsilon_{\mathrm{i}}\right)\right]
$$

Dengan $E\left(u_{i} / \varepsilon_{i}\right)=\frac{\sigma_{u} \sigma_{v}}{\sigma}\left[\frac{f\left(\varepsilon_{i} \lambda / \sigma\right.}{1-F\left(\varepsilon_{i} \lambda / \sigma\right.}-\frac{\varepsilon_{i} \lambda}{\sigma}\right]$

Dimana,

$f(\varepsilon i \lambda / \sigma)=$ fungsi densitas standar normal

$\mathrm{F}\left(\varepsilon_{i} \lambda / \sigma\right)=$ fungsi distribusi standar normal

Sehingga, $0 \leq \mathrm{TE}_{\mathrm{i}} \leq 1$

\section{Penelitian Terdahulu}

Penelitian yang dilakukan oleh Djoko Sudantoko (2010) mengenai "Model Pemberdayaan Industri Batik Skala Kecil di Jawa Tengah (Studi Kasus di Pekalongan)". Hasil yang diperoleh adalah bahwa variabel bahan baku, bahan penolong, tenaga kerja, minyak tanah dan kayu bakar berpengaruh secara positif dan signifikan terhadap produksi industri kecil batik di Pekalongan. Sedangkan untuk variabel peralatan dan luas usaha memberikan tanda negatif dan tidak signifikan. Hasil lainnya adalah bahwa pada umumnya pengrajin batik skala kecil belum seluruhnya melakukan kegiatan secara efisien yang dapat dilihat dari tingkat efisiensi produksi batik. Tingkat efisiensi teknis pelaku usaha batik skala kecil di Pekalongan cukup bervariasi antara 0,607 sampai dengan 0,9597 dengan rata-rata efisiensi teknis sebesar 0,8675 berarti belum efisien.

Penelitian Ketut Sukiyono (2005) mengenai "Faktor Penentu Tingkat efisiensi Teknik Usaha Tani Cabai Merah di Kecamatan Selupu Rejang, Kabupaten Rejang Lebong" memberikan hasil bahwa tingkat efisiensi teknik yang dicapai petani berbeda-beda dari hanya sekitar 7 persen hingga 99 persen, namun secara umum tingkat efisiensi teknik yang dicapai oleh petani cabai merah di daerah penelitian cukup tinggi. Hasil analisis faktor penentu tingkat efisiensi teknis menunjukkan bahwa hanya variabel pendidikan formal yang berpengaruh secara nyata terhadap tingkat efisiensi teknik yang dicapai oleh petani dalam berusahatani cabai merah.

\section{METODE PENELITIAN}

\section{Lokasi Penelitian}

Penelitian ini dilakukan pada UKM batik di Kota Semarang yang tersebar di beberapa wilayah, antara lain: Semarang Selatan, Semarang Timur, Semarang Barat, Mijen, Gunung Pati, Pedurungan, Genuk, Tembalang, Gajah Mungkur, Banyumanik. 


\section{Populasi dan Sampel Penelitian}

Populasi dan sampel pada penelitian ini adalah UKM Batik di Kota Semarang yang berjumlah 67 UKM.

\section{Definisi Operasional Variabel}

Masing-masing variabel dan pengukurannya perlu dijelaskan agar diperoleh kesamaan pemahaman terhadap konsep-konsep dalam penelitian ini, yaitu: (Soedantoko, 2010):

1. Variabel terikat (dependen), yaitu Produksi .

Produksi adalah jumlah produksi kain batik yang dihasilkan dari usaha batik dalam satu bulan yang diukur dalam satuan kodi (1 kodi = 20 potong)

2. Variabel bebas (independen), antara lain:

a. Bahan baku adalah jumlah bahan mentah yang digunakan untuk melakukan proses produksi yang iukur dengan meter $(\mathrm{m})$

b. Bahan penolong adalah bahan-bahan pembantu yang digunakan dalam proses pembatikan selama satu bulan, seperti obat pewarna dan malam/ lilin batik yang diukur dalam satuan $\mathrm{kg}$

c. Tenaga kerja adalah jumlah tenaga kerja yang digunakan dalam proses produksi selama satu bulan yang diukur dengan satuan orang

d. Peralatan adalah peralatan yang digunakan untuk proses produksi batik seperti canting, kompor, wajan dan cap pola yang digunakan untuk proses produksi batik yang diukur dalam satuan unit.

e. Minyak tanah adalah jumlah minyak tanah yang digunakan dalam proses pembuatan batik selama satu bulan yang diukur dalam satuan liter.

f. Kayu bakar adalah jumlah kayu bakar yang digunakan untuk memanaskan air dalam proses pencelupan kain batik (nglorot) untuk menghilangkan malam yang diukur dalam satuan kubik/ bulan

g. Luas Tempat usaha adalah luas tempat yang digunakan dalam proses produksi batik yang diukur dalam satuan $\mathrm{m}^{2}$.

\section{Analisis Efisiensi}

Analisis efisiensi dilakukan dengan menggunakan Stochastic Frontier Production Function digunakan untuk menganalisis efisiensi produksi UKM batik Semarang.

Secara matematis hubungan input-output usaha batik dalam bentuk logaritma adalah sebagai berikut:

$$
\operatorname{Ln} Y=\beta_{0}+\beta_{1} \operatorname{Ln} X_{1}+\beta_{2} \operatorname{Ln} X_{2}+\beta_{3} \operatorname{Ln} X_{3}+\beta_{4} \operatorname{Ln} X_{4}+\beta_{5} \operatorname{Ln} X_{5}+\beta_{6} \operatorname{Ln} X_{6}+\beta_{7} \operatorname{Ln} X_{7}+\varepsilon_{i}
$$

Di mana,

$Y \quad=$ jumlah produksi batik (potong $=2$ meter/potong)

$\beta=$ parameter yang akan ditaksir

$X_{1}=$ bahan baku $(\mathrm{m})$

$X_{2}=$ bahan penolong $(\mathrm{kg})$

$X_{3}=$ tenaga kerja (orang)

$\mathrm{X}_{4}=$ peralatan (unit)

$X_{5}=$ minyak tanah (liter)

$X_{6}=$ kayu bakar (kubik/bulan)

$\mathrm{X}_{7}=$ luas usaha $\left(\mathrm{m}^{2}\right)$

$\varepsilon_{i}=v_{i}-U_{i}$.

Kesalahan ui dianggap negatif dan naik karena pemotongan distribusi normal dengan ratarata nol dan varian $\sigma_{u}^{2}$ yang positif. Hal ini menggambarkan efisiensi teknis produksi sebuah perusahaan. Dengan kata lain kesalahan vi diasumsikan memiliki distribusi normal dengan 
rata-rata nol dan varian $\sigma_{u}^{2}$ yang positif, yang menggambarkan kesalahan pengukuran yang berkaitan dengan faktor di luar kendali yang terdapat dalam proses produksi (Zen et al, 2002 dalam Sudantoko, 2010). Efisiensi teknis dapat diukur dengan menggunakan parameter rasio varians sebagai berikut (Coelli, 1995).

$$
\left.Y=\left(\sigma^{2}\right) / \sigma^{2}\right)
$$

di mana $\sigma^{2}=\sigma_{u^{2}}+\sigma_{v}^{2}$ dan $0 \leq Y \leq 1$

Apabila $y$ mendekati satu, $\sigma_{v^{2}}$ mendekati nol, dan vi adalah tingkat kesalahan dalam persamaan (7) menunjukkan inefisiensi. Dalam hal ini, perbedaan antara pengelolaan dan hasil efisiensi adalah bagian terpenting karena kekhususan dalam pengelolaan. Selanjutnya analisis tersebut untuk mengidentifikasi pengarug dari perbedaan beberapa faktor. Nilai efisiensi teknis dapat diketahui dari hasil pengolahan data dengan Frontier (Versi 4.1.c). Justifikasi nilai efisiensinya adalah (Visvanathan et all, 2001; Coelli, 1998, Sudantoko, 2010): jika nilai efisiensi teknis sama dengan satu, maka penggunaan input dalam usaha sudah efisien.

\section{HASIL DAN PEMBAHASAN}

Hasil analisis efisiensi teknis menunjukkan belum efisien. Hasil analisis efisiensi teknis dengan menggunakan Stochastic Frontier Production Function secara rinci dapat dilihat pada tabel 1. Dari tabel 1 terlihat bahwa sebagian besar parameter-parameter pada fungsi produksi frontier industri kecil batik di Semarang menunjukkan nilai yang positif dan signifikan.

Berdasarkan hasil estimasi fungsi produksi frontier stokastik usaha batik skala kecil, maka koefisien regresi merupakan koefisien elastisitas mengingat modelnya dalam bentuk logaritma. Pembahasan akan diuraikan untuk masing-masing variabel penelitian.

Tabel 1. Hasil Estimasi Fungsi Produksi Frontier

\begin{tabular}{|c|c|c|c|c|}
\hline No & Variabel & Koefisien & Std. error & t-ratio \\
\hline 1 & Konstanta & $-1,63366$ & 0,964289 & 1,694166 \\
\hline 2 & LX1 (Bahan Baku) & 0,33923 & 0,092831 & 3,654308 \\
\hline 3 & LX2 (Bahan Penolong) & $-0,03193$ & 0,109995 & $-0,290320$ \\
\hline 4 & LX3 (Tenaga Kerja) & 0,14146 & 0,055348 & 2,555918 \\
\hline 5 & LX4 (Peralatan) & 0,31539 & 0,049896 & 6,320900 \\
\hline 6 & LX5 (Minyak Tanah) & 0,04874 & 0,078782 & 0,618773 \\
\hline 7 & LX6 (Kayu Bakar) & 0,30227 & 0,067438 & 4,482211 \\
\hline 8 & LX7 (Luas Usaha) & $-0,02638$ & 0,058614 & $-0,450074$ \\
\hline 9 & Y & 0,99999 & 0,000441 & 2263,639 \\
\hline 10 & $\sigma^{2}$ & 0,22381 & 0,003700 & 6,048087 \\
\hline 11 & Log Likelihood 1 & 0,72350 & & \\
\hline 12 & Log Likelihood 2 & 0,787960 & & \\
\hline 13 & Mean TE & 0,889897 & & \\
\hline 15 & $\mathrm{~N}$ & 67 & & \\
\hline
\end{tabular}

Sumber: Data Primer Diolah (2010)

Keterangan :

$\mathrm{TE} \quad=$ Efisiensi teknis

Dalam fungsi produksi faktor-faktor yang berpengaruh nyata dengan arah positif adalah bahan baku, tenaga kerja, dan peralatan. Sedangkan yang berpengaruh positif namun tidak nyata adalah minyak tanah. Bahan penolong dan luas usaha berpengaruh negatif namun tidak nyata. 
Sebagaimana yang diduga, faktor produksi yang pengaruhnya dominan adalah peralatan, tenaga kerja, kayu bakar dan bahan baku dengan koefisien parameternya masing-masing sebesar 0,31539; 0,14146; 0,30227 dan 0,33923. Mengingat bentuk fungsi adalah CobbDouglas, maka nilai koefisien tersebut secara langsung menunjukkan elastisitasnya. Dengan demikian dengan penambahan $1 \%$ peralatan akan meningkatkan produksi batik sebanyak $0,3 \%$; penambahan tenaga kerja $1 \%$ akan meningkatkan produksi batik sebanyak $0,14 \%$; dengan penambahan kayu bakar sebesar $1 \%$ akan meningkatkan produksi sebanyak 0,3\% dan dengan penambahan bahan baku sebesar $1 \%$ akan meningkatkan produksi batik sebanyak $0,33 \%$.

Nilai efisiensi teknis rata-rata adalah sebesar 0,8898. Artinya, rata-rata produktivitas yang dicapai adalah $88,98 \%$ dari frontier yaitu produktivitas maksimum yang dapat dicapai dengan sistem yang dijalankan. Hal ini berarti pelaku usaha batik di Semarang belum seluruhnya melakukan kegiatannya secara efisien sehingga masih dimungkinkan untuk ditingkatkan. Hasil ini sesuai dengan penelitian yang dilakukan Sudantoko (2010) yang menyimpulkan bahwa industri skala kecil dan menengah belum seluruhnya melakukan kegiatan secara efisien.

\section{SIMPULAN}

- Usaha kecil Batik Semarang mempunyai efisien rata-rata adalah sebesar 0,8898, yang artinya belum efisien.

- Faktor produksi yang pengaruhnya dominan adalah peralatan, tenaga kerja, kayu bakar dan bahan baku. Sedangkan minyak tanah, bahan penolong dan luas usaha tidak berpengaruh terhadap produksi batik.

- Agar dapat meningkatkan produktivitas secara nyata maka dibutuhkan inovasi teknologi/ peralatan yang lebih maju. Namun hal ini tidak mudah, karena memerlukan terobosan-terobosan teknologi yang lazim diharapkan dari aktivitas penelitian. Selain itu juga perlu dilakukan pembinaan masyarakat terhadap kerajinan batik yang baik agar muncul tenaga kerja-tenaga kerja yang memiliki keahlian dalam membatik.

\section{DAFTAR PUSTAKA}

Afifah, Nunuy N. (2009). Peran Kewirausahaan Dalam Memperkuat UKM Indonesia Menghadapi Krisis Finansial Global. Dalam Working Paper in Accounting and Finance, Universitas Padjadjaran, Bandung

Aigner, D.J., C.A.K. Lovell, and P.Schmidt, 1977, Formulation and Estimation of Stochastic Frontier Production Function Models, Journal of Econometrics., $6: 21-37$.

Battase, G.E. and Coelli, T.J. (1995) Frontier Production Functions, Journal of Production Analysis, $3: 153-169$.

Batra, Geeta and Tan, Hong. (2003). SME Technical Efficiency and Its Correlates: CrossNational Evidence and Policy Implications. World Bank Institute Working Paper.

Coelli, T.J., (1996), A Guide to Frontier Version 4.1 : A Computer Program for Stochastic Frontier Production and Cost Function Estimation. Centre for Efficiency and Productivity Analysis. University of New England - Armidale. New South Wales.

Farrell, M.J. (1957). The Measurement of Productive Efficiency. Journal of the Royal Statistical Society A 120, part 3: pp. 253-281.

Jawatengah go.id. (2004).

Jondrow, J., Lovell, C.A.K., Materov, I.S., and Schmidt, P., (1982), On Estimation of Technical Inefficiency in The Stochastic Frontier Production Function Model, Journal of Econometrics, $19: 233-236$. 
Karsidi, Ravik. (2005). Pemberdayaan Masyarakat Untuk Usaha Kecil Dan Mikro (Pengalaman Empiris Di Wilayah Surakarta, Jawa Tengah). Makalah. Disampaikan Dalam Seminar Nasional "Pengembangan Sumberdaya Manusia Indonesia" Program Studi Ilmu Penyuluhan Pembangunan di Sekolah Pascasarjana IPB Bogor pada tanggal 21 September 2005

Komaruddin, (1986), Analisis Manajemen Produksi, Alumni, Bandung

Lovel, C.A.K. (1993). Production Frontiers and Productive Efficiency. The Measurement of Productive Efficiency. Oxford University Press, p.3-67

Matambalya, Francis and Wolf, Susanne. (2001). The Role of ICT for The Performance of SMES in East Africa (Empirical Evidence From Kenya and Tanzania). ZEF-Discussion Papers on Development Policy, no. 42

Meeusen, W. and J. Van den Broek, (1977), Efficiency Estimation from Cobb-Douglas Production Function with Composed Error, International Economic Review, 18 : 435 - 444.

Pascoe, Sand L. Coglan, (2002), The Contribution of Un measurable Inputs to Fisheries Production: An analysis of Technical Efficiency of Fishing Vessels in The English Channel. American Journal of Agricultural Economics, 84(3) : $585-597$.

Pemkot Semarang. (2009)

Radam, Alias, Abu, Mimi Liana. And Abdulah, Amin Mahir. (2008). Technical Efficiency of Small and Medium Enterprise in Malaysia: A stochastic Frontier Production Model. International Journal of economics and Management. P. 395-408. ISSN 1823-836X

Samad, Q.A and Patwary F K.(2003). Technical Efficiency in Textile Industry of Bangladesh: an Application of Frontier Production Function. International Journal of Information and Management Science. Vol,14 No.1 p.19-30

Soedantoko, Djoko.(2010). Model Pemberdayaan Industri Batik Skala Kecil di Jawa Tengah (Studi Kasus di Pekalongan). Disertasi. Program Pascasarjana Universitas Diponegoro Semarang (Tidak dipublikasikan)

Soekartawi .(2003). Teori Ekonomi Produksi, dengan pokok bahasan analisis Fungsi CobbDouglas. Rajawali Pers. Jakarta.

Sukiyono, Ketut. (2004). Analisa Fungsi Produksi dan Efisiensi Teknis: Aplikasi Fungsi Produksi Frontier Pada Usaha Tani Cabai di Kecamatan Selupu Rejang, Kabupaten Rejang Lebong. Jurnal ilmu-ilmu Pertanian Indonesia, Vol.6 No.2.

Waspada Online.(2008). Batik Sebagai Ikon Nasional. http://www.waspada.co.id 